\title{
MANFAAT PEMBERIAN JUS JAMBU BIJI TERHADAP KENAIKAN NILAI KADAR HEMOGLOBIN PADA IBU HAMIL
}

\author{
Tria Nopi Herdiani, Desi Fitriani, Ruri Maiseptya Sari, Vitri Ulandari \\ Program Studi Sarjana Terapan Kebidanan STIKes Tri Mandiri Sakti Bengkulu, 085273303085. \\ Email : direja.mandira1415@gmail.com
}

\begin{abstract}
ABSTRAK
World Health Organization (WHO) tahun 2014, melaporkan bahwa terdapat 52\% ibu hamil mengalami anemia di Negara berkembang. Solusi berkala untuk mengatasi anemia pada ibu hamil diantaranya dengan pemberian Tablet Fe dan vitamin zat besi dari jus jambu. Penelitian ini bertujuan untuk mengetahui pengaruh pemberian jus jambu biji terhadap perubahan kadar hemoglobin ibu hamil. Metode penelitian menggunkan Quasi Eksperiment dengan Non-randimized control Grup Pre test-Post test Design. Jumlah sampel yaitu 30 orang ibu hamil yang di bagi menjadi dua kelompok yaitu 15 orang ibu hamil pada kelompok kontrol dan 15 orang ibu hamil pada kelompok intervensi. Analisis menggunakan Uji Paried t-test dan Independent T-Test. Hasil penelitian rata -rata peningkatan kadar hemoglobin pretest dan posttest kelompok kontrol 8,867 $\mathrm{g} / \mathrm{dl}$ dan 10,327 g/dl, dan rata-rata peningkatan kadar hemoglobin pretest dan posttest kelompok perlakuan 8,620 g/dl dan $11,580 \mathrm{~g} / \mathrm{dl}$ sehingga ada perbedaan kenaikan kadar hemoglobin kelompok kontrol dan perlakuan nilai rata - rata selisih kadar hemoglobin sebelum dan sesudah pada kelompok kontrol 1,46g/dl dan rata - rata selisih kadar hemoglobin sebelum dan sesudah kelompok perlakuan 2,96 g/dl dengan nilai $P$ value 0,031 . Ada pengaruh pemberian jus jambu biji terhadap kenaikan nilai kadar hemoglobin pada ibu hamil.
\end{abstract}

Kata kunci: ibu hamil; jus jambu biji; kadar hemoglobin

\section{THE EFFECT OF GMNGJ AMBUSEEDS ONINCREASINGTHE VALUE OF HEMDGLOBINLEVELS IN PREGNANT}

\begin{abstract}
World Health Organization (WHO) in 2014, reported that there were 52\% of pregnant women experiencing anemia in developing countries. Periodic solutions to overcome anemia in pregnant women include giving Fe tablets and iron vitamins from guava juice. The purpose of this study is to determine the Effect of Providing Guava Juice to Improvement of Haemoglobin Level on Pregnant Mother. This method used Quasi Experiment with Non-Randomized Control Group Pre test-Post test design. Sampling technique in this study used Quota Sampling with sample of 30 people pregnant mother who divided by 2 group that were 15 people pregnant mother on control group and 15 people pregnant mother on intervention group. Data analysis used with Paired T-Test and Independent T-Test. The result of this study showed average Improvement Value of Haemoglobin pretest and posttest on control group were 8,867 g/dl and 10,327 g/dl, and average Improvement Value of Haemoglobin pretest and posttest on intervention group 8,620 g/dl and 11,580 g/dl so that there is different Improvement Value of Haemoglobin on control group and intervention where value average of Haemoglobin level before and after on control group were 1,46 and value average of Haemoglobin level before and after on intervention group were 2,96 with $p$-value $=0,031$. There is Effect of Providing Guava Juice to Improvement Value of Haemoglobin Level on Pregnant Mother.
\end{abstract}

Keywords: guava juice; haemoglobin level; pregnant mother 


\section{LATAR BELAKANG}

World Health Organization (WHO) tahun 2014, melaporkan bahwa terdapat 52\% ibu hamil mengalami anemia di Negara berkembang. Jumlah perempuan meninggal karena komplikasi selama kehamilan dan persalinan mengalami penurunan sebesar $45 \%$ dari perkiraan 523.000 pada tahun 2010 dan 289.000 pada tahun 2013. Angka kematian ibu sudah mengalami penuruan, namun masih jauh dari target MDGs yang menetapkan AKI di bawah 100 di tahun 2015.Rencana Pembangunan Jangka Menengah Nasional (RPJMN) yang ditetapkannya RPJMN 20152019 maka Kementerian Kesehatan menyusun Renstratahun 2015-2019 (Darmaisari, 2016).

Survei Demografi Kesehatan Indonesia (SDKI) tahun 2012, Angka Kematian Ibu (AKI) di Indonesia mencapai 359 per 100.000 kelahiran, dan terjadi penurunan sebesar 137 per 100.000 kelahiran hidup dengan jumlah total kematian 6.400 pada tahun 2015. Angka tersebut masih jauh dari target Rancangan Pembangunan Jangka Menengah (RPJMN) tahun 2014 sebesar 118 per 100.000 kelahiran hidup dan target Milenium Develpomen Goals (MDG's) sebesar 102 per 100.000 kelahiran hidup tahun 2015 (SDKI, 2012).

Kondisi janin dalam kandungan seorang ibu sangat dipengaruhi keadaan gizi ibu sebelum dan selama mengandung. Wanita hamil berisiko mengalami Kekurangan Energi Kronik (KEK) yang bisa menyebabkan berisiko menjadi penyebab langsung kematian ibu, karena anemia pada kehamilan bisa menyebabkan perdarahan yang nantinya bisa mengakibatkan kematian baik pada ibu maupun janin (Kemenkes RI, 2015).

Ibu hamil yang menderita anemia memiliki kemungkinan akan mengalami perdarahan postpartum. Frekuensi perdarahan post partum (5-15\%) dari seluruh persalinan, penyebab atonia uteri memiliki angka presentasi paling tinggi dari yang lainnya (50-60\%), retensio plasenta (16-17\%), sisa plasenta (23-24\%), laserasi jalan lahir (4-5\%), dan kelainan pembekuan darah $(0,5-0,6 \%)$ sedangkan persentase perdarahan karena anemia selama kehamilan (15-20\%). Mengingat besarnya dampak buruk dari Anemia Defisiensi Zat Besi pada wanita hamil dan janin, oleh karena itu perlu kiranya perhatian yang cukup terhadap masalah ini (Nugroho, 2012).

Anemia pada kehamilan tidak dapat dipisahkan dengan perubahan fisiologis yang terjadi selama proses kehamilan, umur janin, dan kondisi ibu hamil sebelumnya. Pada saat hamil, tubuh akan mengalami perubahan yang signifikan, jumlah darah dalam tubuh meningkat sekitar 20 - $30 \%$, sehingga memerlukan peningkatan kebutuhan pasokan besi dan vitamin untuk membuat hemoglobin $(\mathrm{Hb})$. Ketika hamil, tubuh ibu akan membuat lebih banyak darah untuk berbagi dengan bayinya. Tubuh memerlukan darah hingga $30 \%$ lebih banyak dari pada sebelum hamil. Beberapa faktor yang dapat menyebabkan terjadinya anemia kehamilan diantaranya gravid, umur, paritas, tingkat pendidikan, status ekonomi dan kepatuhan konsumsi tablet Fe (Krisnawati, 2015).

Efek anemia pada ibu dan janin bervariasi dari ringan sampai berat. Bila kadar hemoglobin lebih rendah dari $6 \mathrm{~g} / \mathrm{dl}$, maka dapat timbul komplikasi yang signifikan pada ibu dan janin. Kadar hemoglobin serendah itu tidak dapat mencukupi kebutuhan oksigen janin, menyebabkan gagal jantung pada ibu, terjadinya hambatan pertumbuhan janin baik sel tubuh maupun sel otak., abortus, lamanya waktu partus karena kurangnya daya dorongan rahim, perdarahan post partum, rentan terjadi infeksi dengan hemoglobin kurang dari $4 \mathrm{~g} / \%$ (Proverawati, 2011).

Sangat penting strategi dan solusi berkala untuk mengatasi anemia pada ibu hamil, diantaraya dengan pemberian vitamin zat besi di mulai dengan memberikan tablet 1 Fe sehari sesegera mungkin setelah rasa mual hilang. Tiap tablet mengandung Fe So4 320 mg (zat besi $60 \mathrm{mg}$ ) dan asam folat $500 \mathrm{mg}$, minimal masing-masing 90 tablet. Sebaiknya tablet besi tidak di minum bersamaan dengan teh atau kopi karena hanya akan mengganggu penyerapan zat besi (Prawirohardjo, 2014).

Di Provinsi Bengkulu pada tahun 2016 secara absolut jumlah kematian ibu yaitu sebanyak 41orang, yang terdiri dari kematian ibu hamil sebanyak 6 orang, kematian ibu bersalin sebanyak 17 orang dan kematian ibu 
nifas sebanyak 18 orang, sedangkan angka kematian ibu di Provinsi Bengkulu pada tahun 2016 yaitu sebesar 17 per $100.000 \mathrm{KH}$, mengalami penurunan cukup signifikan dari tahun 2015 yaitu 137 per 100.000 KH (Dinas Kesehatan Provinsi Bengkulu, 2016).

Dari survey awal yang telah dilakukan pada tanggal 19 Mei di Puskesmas Basuki Rahmad terdapat 6 ibu hamil yang datang ke puskesmas untuk memeriksakan kehamilannya, 4 diantaranya ibu hamil yang mengalami anemia yang disebabkan oleh kurangnya perhatian ibu hamil terhadap bahaya anemia dalam kehamilan dan 2 ibu hamil yang mengalami anemia yang disebabkan oleh kurangnya pengetahuan ibu terhadap pentingnya menjaga kadar $\mathrm{Hb}$ tetap normal selama masakehamilan.

Berdasarkan uraian latar belakang diatas peneliti tertarik untuk mengambil judul penelitian Pengaruhpemberian jus jambu biji terhadap kenaikan nilai kadar hemaglobin pada ibu hamil. Tujian Penelitian ini untuk mengetahui pengaruh pemberian jus jambu biji terhadap perubahan kadar hemoglobin ibu hamil.

\section{METODE PENELITIAN}

Penelitian ini dilaksanakan di wilayah kerja Puskesmas Basuki Rahmad Kota Bengkulu. metode penelitian Quasi Eksperiment dengan menggunakan pendekatan Non-randimized control Grup Pre test-Post test Design. Populasi dalam penelitian ini adalah 253 ibu hamil Trimester III di wilayah kerja Puskesmas Basuki Rahmad Kota Bengkulu pada bulan Januari Juni 2018. Teknik pengambilan sampel menggunakan Quota Sampling. Sampel penelitian yaitu 30 orang ibu hamil yang dibagi menjadi dua kelompok yaitu 15 orang ibu hamil pada kelompok kontrol (kelompok ibu hamil yang tidak diberikan jus jambu biji ) dan 15 orang ibu hamil pada kelompok intervensi (kelompok ibu hamil yang diberikan jus jambu biji ) Data yang digunakan adalah data primer.Data primer diperoleh dengan cara mengukur kadar hemoglobin sebelum dan sesudah diberikan jus jambu biji. Instrument yang digunakan adalah Easy Touch Blood Hemoglobin. Waktu penelitian dilaksanakan pada bulan Juni-Juli 2018. Uji statistik digunakan adalah uji Independent T-Test.

\section{HASIL}

Hasil test of nomarlity di atas didapat nilai signifikan pada uji Shapiro-Wilk dengan sig. $(p)=0,389>\alpha=0,05$. Sehingga Ho diterima dan $\mathrm{Ha}$ ditolak. Jadi sampel berasal dari populasi berdistribusi normal pada taraf signifikan 0,05.

Analisis Univariat dilakukan untuk melihat gambaran distribusi frekuensi ibu hamil yang mengkonsumsi jus jambu biji di wilayah kerja Puskesmas Basuki Rahamd Kota Bengkulu.

\section{Tabel 1 Distribusi Frekuensi Kadar Hemoglobin Pada Ibu Hamil Trimester III yang Mengkonsumsi Jus Jambu Biji dan Tablet Fe}

\begin{tabular}{|c|c|c|c|c|}
\hline \multirow{5}{*}{ Variabel } & Konsumsi & & & \\
\hline & Jus & & & \\
\hline & Jambu & $\mathrm{N}$ & Mean $\pm S D$ & Median \\
\hline & Biji dan & & & \\
\hline & Tablet Fe & & & \\
\hline \multirow{2}{*}{$\begin{array}{c}\text { Kadar } \\
\text { Hemoglobin }\end{array}$} & Sebelum & 15 & 9,070 & 8,700 \\
\hline & Sesudah & 15 & $11,580 \pm 1,5970$ & 11,900 \\
\hline
\end{tabular}

Berdasar tabel 1 dapat diketahui bahwa dari 15 orang ibu hamil Trimester III yang Mengkonsumsi Jus Jambu Biji dan Tablet Fe memiliki rata - rata nilai kadar Hemoglobin sebelum perlakuan $8,620 \mathrm{~g} / \mathrm{dl} \pm S D 2,5417$ dengan nilai Median 8,7 g/dl,rata - rata nilai kadar Hemoglobin setelah perlakuan 11,580 $\mathrm{g} / \mathrm{dl} \pm$ SD 1,5970 dengan nilai Median 11,9 g/dl.

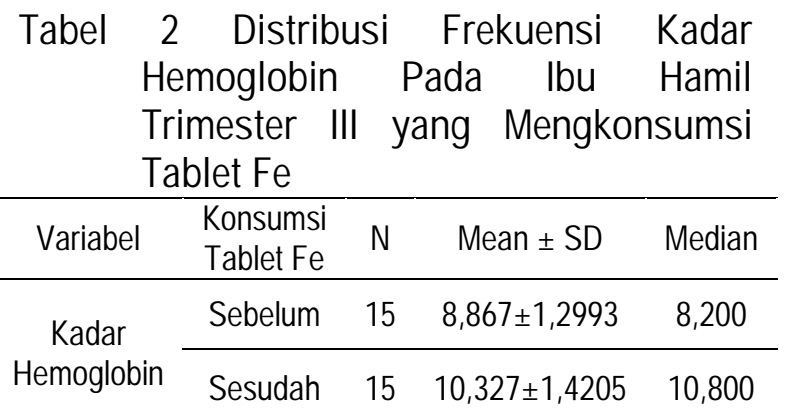


Berdasarkan Tabel 2 dapat diketahui bahwa dari 15 orang ibu hamil Trimester III yang Mengkonsumsi Tablet Fe memiliki rata - rata nilai kadar Hemoglobin sebelum perlakuan 8,867 g/dl $\pm S D$ 1,2993 dengan nilai Median 8,2 $\mathrm{g} / \mathrm{dl}$, rata - rata nilai kadar Hemoglobin setelah perlakuan 10,327 $\mathrm{g} / \mathrm{dl} \pm$ SD 1,4205 dengan nilai Median 10,8 g/dl.

Analisis Bivariat ini dilakukan untuk mengetahui pengaruh antara variabel independent (konsumsi jus jambu biji dan tablet $\mathrm{Fe}$ ) denganvariabel dependent (konsumsi tablet $\mathrm{Fe}$ ) pada ibu hamil yang mengkonsumsi jus jambu biji di wilayah kerja Puskesmas Basuki Rahamd Kota Bengkulu.

Tabel 3 Pengaruh Kadar Hemoglobin Pada Ibu Hamil Trimester III yang Mengkonsumsi jus jambu biji dan tablet Fe dengan hanya Mengkonsumsi Tablet Fe

\begin{tabular}{lccccc}
\hline \multicolumn{1}{c}{ Faktor } & $\mathrm{N}$ & Mean & $\begin{array}{c}\text { Std } \\
\text { Deviation }\end{array}$ & $\mathrm{T}$ & $\begin{array}{c}\mu \\
\text { value }\end{array}$ \\
\hline $\begin{array}{l}\text { Mengkonsumsi } \\
\text { jus jambu biji } \\
\text { dan tablet Fe }\end{array}$ & 15 & 11,580 & 1,5970 & & \\
\hline $\begin{array}{l}\text { hanya } \\
\text { Mengkonsumsi } \\
\text { Tablet Fe }\end{array}$ & 15 & 10,327 & 1,4205 & 0,031 \\
\hline
\end{tabular}

Berdasarkan tabel 3 diketahui bahwa dari 30 Ibu Hamil Trimester III, 15 Ibu Hamil Trimester III yang Mengkonsumsi jus jambu biji dan tablet Fe diperoleh rata - rata nilai kadar Hemoglobin 11,580 dengan standar deviasi 1,597 dan ratarata nilai kadar Hemoglobin hanya Mengkonsumsi Tablet Fe 10,327 g/dl dengan standar deviasi 1,4205.

Berdasarkan hasil uji statistik diperoleh $\mu=0,031<\alpha \quad 0,05$ berarti signifikan, maka $\mathrm{Ha}$ diterima sehingga ada pengaruh pemberian jus jambu biji terhadap kenaikan nilai kadar hemoglobin pada ibu hamil Trimester III di wilayah Puskesmas Basuki Rahmad Kota Bengkulu.

\section{PEMBAHASAN}

Berdasarkan hasil penelitian menunjukkan bahwa ada perbedaan kenaikan kadar hemoglobin pada kelompok kontrol dan perlakuan dimana nilai rata - rata selisih kadar hemoglobin sebelum dan sesudah pada kelompok kontrol yaitu 1,46 g/dl dan rata - rata selisih kadar hemoglobin sebelum dan sesudah pada kelompok perlakuan yaitu 2,96 g/dl dengan nilai $\rho$-value $=0,031<\alpha \quad 0,05$ sehingga Ha diterima artinya ada pengaruh pemberian jus jambu biji terhadap kenaikan nilai kadar hemoglobin pada ibu hamil Trimester III di wilayah Puskesmas Basuki Rahmad Kota Bengkulu. Berpengaruhnya jus jambu biji ini terhadap peningkatan kadar hemoglobin juga dikaitkan oleh kandungan gizi dari jus jambu biji itu sendiri.Menurut Sianturi (2012) buah jambu biji enrah engandung senyawa yang dapat meningkatkan kadar hemoglobin dalam darah antara lain, zat besi vitamin $C$, vitamin $A$, tembaga dan fosfor.

Hasil penelitian serupa yang pernah dilakukan oleh Ningtyastuti, E (2013) yang meneliti tentang ada pengaruh pemberian jus jambu biji terhadap kenaikan nilai kadar hemoglobin pada ibu hamil, dalam penelitian tersebut yang menyatakan bahwa ada pengaruh pemberian jus jambu biji terhadap kenaikan nilai kadar hemoglobin pada ibu hamil. Hasil penelitian ini didukung juga oleh penelitian yang dilakukan Yusnaini (2014) tentang ada pengaruh pemberian jus jambu bijimerah terhadap perubahan peningkatan kadar $\mathrm{Hb}$ darah ibu hamil anemia.

Berpengaruhnya jus jambu biji ini terhadap peningkatan kadar hemoglobin juga dikaitkan oleh kandungan gizi dari jus jambu biji itu sendiri. Menurut Sianturi (2012) buah jambu biji merah engandung senyawa yang dapat meningkatkan kadar hemoglobin dalam darah antara lain, zat besi 1,1 mg, vitamin C $87 \mathrm{mg}$, vitamin A $25 \mathrm{IU}$, Vitamin B1 0,02 mg fosfor 28 mg. 
Zat besi merupakan mineral yang diperukan untuk mengangkut oksigen ke seluruh tubuh jika kekurangan zat besi dalam tubuh seseorang maka akan mengalami penurunan system kekebalan tubuh dan sering merasa lesu hai ini juga yang menjadi salah satu penyebab anemia.

Pada masa kehamilan trimester III terjadi penurunan kadar hemoglobin dan hematokrit yang menyebabkan viskositas darah juga menurun. Pada masa ini konsentrasi hemoglobin ibu sangat penting untuk diperhatikan ibu hamil cenderung memiliki kadar hemoglobin yang lebih rendah dibandingkan dengan ibu yang tidak hamil.

Beberapa zat gizi yang diperlukan dalam pembentukkan sel darah merah zat besi atau Fe vitamin B12 dan asam folat adalah zat yang terpenting di samping itu tubuh juga memerlukan sejumlah kecil vitamin $\mathrm{C}$ riboflavin dan tembaga serta keseimbangan hormon terutama eritropoietin (hormon yang merangsang pembentukan sel darah merah).Tanpa zat gizi dan hormon tersebut pembentukkan sel darah merah akan berjalan lambat tidak menukupi dan selnya bisa memiliki kelaian bentuk dan tidak mampu mengangkut oksigen sebagaimana mestinya sehingga dapat menimbulkan anemia (Yusnaini, 2014).

\section{KESIMPULAN DAN SARAN}

Ada pengaruh pemberian jus jambu biji terhadap kenaikan nilai kadar hemoglobin pada ibu hamil. Saran bagi lbu hamil dapat menjadikan jus jambu biji sebagai pilihan alternatif dalam meningkatkan kadar hemoglobin selama masa kehamilan sehingga anemia pada masa kehamilan dapat diatasi sejak awal

\section{REFERENSI}

Darmaisari, N.(2016).Efektifitas Jus Jambu Biji Merah Tehadap Peningkatan Kadar Hemoglobin Ibu Hamil Dengan Anemia DiWilayah Kerja Puskesmas Ambacang Padang.STIKES Prima Nusantara.

Dinkes Provinsi Bengkulu. (2016). Profil Dinas Kesehatan Provinsi Bengkulu Tahun 2016. Provinsi Kesehatan Provinsi Bengkulu.

Ningtyastuti, E (2013). Pengaruh Mengkonsusi Jus Jambu Biji Merah Terhadap Kenaikan Nilai Kadar Hemoglobin Pada Ibu Hamil Di Kelurahan Bandung Kecamatan Ngrampal Kabupaten Seragen. Jurnal Kebidanan Klaten.

Nugraheni, E. (2010). Asuhan Kebidanan Patologi. Yogyakarta:Pustaka Rihama.

SDKI. (2012). Survei Demografi Kesehatan Indonesia. Jakarta.

Sianturi,(2012).Pengaruh Vitamin C Pada Penyerapan Zat Besi Medan : FIPA UNM.

Suparni, I. (2017). Seri Herbal Nusantara: Herbal Kalimantan - Ramuan Tradisional Asli Dari Kalimantan. Yogyakarta: Rapha Publishing.

WHO. (2014). Iron Deficiency Anemia : Assessemen, Prevention and Control A Give For Programme Meneger Geneva, World Health Organization.

Yusnaini, (2014).Pengaruh Konsumsi Jus Jambu Biji Merah Terhadap Perubahan Peningkatan Kadar Hb Darah Ibu Hamil Anemia Yang Endapatkan Supleentasi Tablet Fe.Jurnal Kesehatan IImiah Nasuwakes. 